\title{
An evaluation of the impact of health insurance on health care in Akwa Ibom State
}

\author{
Article by Amaka Agusiobo \\ Master in Public Health, Texila American University, Nigeria \\ Email:amakaagusiobo2@yahoo.com
}

\begin{abstract}
The impact of health insurance show positive effects on access and utilization but, it is difficult to generalize the impact as the enrollment has not been as wide spread as planned. Still, given the available literature, we do expect to find an average but not wide spread impact on access and utilization of health care this will improve when the State Governments and the informal sector is integrated in the scheme.
\end{abstract}

\section{Background}

\section{Introduction}

Prior to the global oil boom of the 1980s and ensuing economic recession, access to health care in Nigeria was readily available at public hospitals and clinics at no charge. All patients received equal and appropriate care, consistent with the conditions presented regardless of socioeconomic status. Patients only paid for prescription drugs and supplies that were unavailable at public dispensaries. However, by 1985 free health care was stopped and user fees were introduced as the bedrock for health care financing in the country. The consequence of this change was that a vast majority of the population was denied access to health care, causing a swift plunge of all the vital health indices. Successive years brought no respite; rather the situation has gotten even grimmer with the emergence and reemergence of diseases. Over the years, widespread poverty and escalating cost of health care engendered an astronomical number of morbidities and mortalities, many resulting from diseases and illnesses, which were treatable at little or no significant cost. These factors provoked agitations and calls for health sector reforms leading policy makers to develop a national health insurance program as a possible panacea to access and financial challenges.

\section{History}

The idea of a national health insurance program was first floated in 1962, at a time when the health care needs of Nigerians were readily met by the government. Therefore, there no need for an overhaul of a system that delivered services satisfactorily. In 1984 the idea was resurrected by the National Council on Health, the highest policy-making body on health, determined to find new ways to generate additional revenue to augment declining funds available for health care, an emerging problem at the time. A committee was inaugurated to advise the government on the feasibility and desirability of a national health insurance program. The committee made consultations and held negotiations led to the enactment of the National Health Insurance Scheme (Scheme)Decree (now, Act)35 of 1999 (NHIS Act), establishing a system of funding health care in Nigeria.

Subscription to the programs of the Scheme was optional except for employees in the public sector and organized private sector. The system envisaged a shared responsibility between the people and the government - for financing quality health care. However, due to logistic difficulties, coupled with widespread skepticism about the Scheme, implementation did not materialize until June 2005.

The purpose of this research was to assess the role of health insurance on health care and to evaluate the success of the NHIS and the role of the HMOs in the uptake of health insurance 
South American Journal of Public Health

Special Edition May 2016

as expressed in the NHIS Act, has prospects for ensuring that "every Nigerian has access to good health care services."

Though the NHIS looked like a panacea it is fraught with weaknesses, which can render the goals unattainable. More succinctly, the Scheme lacks the requisite policy and legal frameworks for realizing many of the goals it sets out to accomplish. But despite these critical flaws, it is possible for the HMOs to make the NHIS a success.

\section{Objectives and implementation of the scheme}

The Scheme has ambitious goals the objectives of the Scheme are to:

(a) Ensure that every Nigerian has access to good health care services;

(b) Protect families from the financial hardship of huge medical bills;

(c) Limit the rise in the cost of health care services;

(d) Ensure equitable distribution of health care costs among different income groups;

(e) Maintain high standards of health care delivery services within the Scheme;

(f) Ensure efficiency in health care services;

(g) Improve and harness private sector participation in the provision of health care Services

(h) Ensure equitable distribution of health facilities within the Federation;

(i) Ensure appropriate patronage of all levels of health care; and

(j) Ensure the availability of funds to the health sector for improved services.

These goals respond to various elements of the health sector difficulties in Nigeria and are generally considered crucial to improving access. However, as experience has shown, identifying the problems or even constructing well-polished remedial measures is one thing; actual implementation and its impact on the general public is what this study seeks to discover.

At the apex of administration in the country is the NHIS, a body corporate with a mandate to improve the health of Nigerians by providing quality and affordable health insurance. Management of the Scheme is vested in a Governing Council, consisting of representatives drawn from both the public and private sectors, including the Ministries of Finance, Health and Labor; Health Maintenance Organizations (HMOs); health care providers and the general population. The NHIS Act sets out broad governance framework, leaving the Scheme with the responsibility to promulgate detailed guidelines for implementing its various programs or health plans. Acting under this authority, the Scheme issued “Operational Guidelines” for implementation of the programs in 2005 The Guidelines elaborate, the levels and types of participation in the different programs of the Scheme, applicable benefit packages and regulations for HMOs and health care providers.

\section{Salient features of the scheme}

The Role of HMOs

As in managed health systems elsewhere, HMOs occupy a pivotal position in the implementation of NHIS in Nigeria. HMOs are defined as private or public incorporated companies registered by the Scheme solely for the purpose of managing the provision of health care as specified by the Scheme. S.19 of the NHIS Act stipulates the conditions for registration of these companies. A company seeking registration as a HMO is required, to register with the Corporate Affairs Commission; provide evidence of fidelity insurance with an NHIS approved company, up to the value of its paid-up share capital; possess competent workforce and necessary infrastructure; and pay the stated fees. In addition, the company must show evidence of financial viability. It must satisfy the minimum paid-up share capital requirement, maintain an operational account with an NHIS-accredited bank and undertake not to engage in any business other than the business of health care management.

It is reassuring that registration as HMOs is available only to groups of persons or organizations of professionals and not the ability to mobilize start-up capital. By shielding the funds contributed by participants in the Scheme from unscrupulous elements, these measures 
serve to infuse confidence in potential enrollees that the care advertised under the various plans will in fact be provided upon demand.

The responsibilities of HMOs in the operation of the Scheme are clearly spelt out in S.20 of the NHIS Act. HMOs are responsible for collection of contributions from registered employers and employees as well as voluntary contributors, making payments to health care providers, rendering monthly returns on its activities to the NHIS, contracting with providers for delivery of services and assuring the quality of such services. Except for programs for urban self employed and rural community residents, which are under the direct management of the Scheme, the administration of the rest of the programs is entrusted to HMOs. To ensure transparency, HMOs are required to provide free access to their bank account information and forward to the Scheme, on monthly basis, their bank statements and, within six months of the end of HMOs' accounting year, their annual reports and audited accounts.

\section{Covered health care benefits}

For participants in any of the formal sector programs, the following minimum benefit package is provided:

(a) Outpatient care (including consumables);

(b) Prescription drugs as contained in the national essential drug list;

(c) Diagnostic tests as contained in the NHIS diagnostic test list;

(d) Maternal care (including antennal and post-natal), limited to four (4)live births per insured contributor or couple;

(e) Immunization services as contained in the national program on immunization;

(f) Family planning;

(g) Consultations with specialists such as physicians, pediatricians, surgeons, et al;

(h) Hospital care in a standard ward for a stated length of time, for physical and mental Disorders;

(i) Eye examination and care, excluding prescription glasses and contact lenses;

(j) Prostheses (limited to locally-produced artificial limbs); and,

(k) Dental care.

The list of benefits derivable by enrollees and their dependents is consistent with the goals of the National Health Policy which, following WHO's model, prioritizes primary health care as "the basic philosophy and strategy for national health development" as well as other national initiatives aimed at meeting the benchmarks outlined by the MDGs. This is crucial in light of the fact that Nigeria remains among the countries currently struggling to meet the benchmarks of the health-related aspects of the MDGs, particularly in the areas of reducing child mortality and improving maternal health - two intimately related challenges against which concrete solutions are yet to be found. Secondary and tertiary care are also covered, but can be accessed only upon appropriate referrals.

The NHIS system is based on a capitation payment (fixed sum per person regardless of services) to accredited primary care providers for most of the basic benefit package. The current primary care capitation fee is N550 per enrollee per month with no variation for location or enrollee demographics. From this capitation, the primary care provider is expected to pay for his or her primary care services, antenatal and postnatal childcare and all required drugs from the essential drug list, and the first 15 days of required hospitalization. The NHIS reimburses the provider for up to four routine deliveries.

The selected primary care provider acts as a gatekeeper for referral services (to consultant specialists), which the HMO pays a fee for out of a portion of the full premium set aside to cover these costs. A woman's first pregnancy is to be referred to a specialist for delivery, although the primary care physician is to perform antenatal care until week 37 unless a complication develops. This first delivery and any C-sections are referred to a specialist, which the HMO pays. The HMO also pays fees for service for an additional 14 days of hospitalization (days 15 to 29), up to an annual cap of 29 days of inpatient care. Family planning consultation is included in the primary care capitation. 
South American Journal of Public Health

Special Edition May 2016

All well-child care and routine childhood illness care is included in the primary care capitation. The primary care provider is to give all required immunizations at no cost to the patient, obtaining the vaccine from government stocks at no charge.

\section{Criticism}

Family planning supplies are not an NHIS benefit; the provider can charge fees for services including IU Dinsertions and sterilization though NHIS has no policy against family planning. Some have criticized the policy because it appears that many services were left out of the reimbursement package (to keep premiums low and the system sustainable)and antiretroviral therapy is not included.

The NHIS covers essential drugs, with the patient to make a 10 percent copayment and the provider to pay the remaining 90 percent out of the capitation. The NHIS rules require the separation of prescribing and dispensing; the NHIS primary care provider is supposed to refer patients to a pharmacist unless his or her facility has a licensed pharmacy. The primary care provider arranges to pay the pharmacist out of his or her capitation for essential drugs. The NHIS does not cover prescription drugs not on the essential drugs list. This scheme for drug reimbursement is not feasible in many areas of Nigerians because of the shortage of licensed pharmacies. Essential drugs obtained through Patent Medicine Vendors are not reimbursable in the NHIS. Some doctors also worry that patients will not or cannot afford to travel to a pharmacy and they may not fill their prescription. Pharmacists are unhappy about being dependent on primary physicians for their payments. Now they will have to market themselves to physicians to be eligible for NHIS reimbursements. Consumers are not able to fill their prescriptions where they like, but instead will be limited to using pharmacists with whom their physician has a business relationship for reimbursement.

\section{Current situation}

Enrollees are assigned to an HMO according to their place of work. HMOs provide a list of primary care providers and enrollees pick available providers from this list. Enrollees receive photo ID cards (for a fee). Frequent switching of primary care providers is permitted. Most HMOs see a major skills deficit in primary care providers in terms of prevention, counseling, and patient management. Enrolling providers into the scheme has been led by HMOs who have struggled with how to accredit providers without investing in expensive quality assessments. State-level branches of the NHIS are responsible for accrediting providers. Nursing homes and maternity homes can become accredited NHIS primary care providers. State facility licensure is a prerequisite for accreditation, but established HMOs feel that some facilities are being accredited that should not be (and that would not be accredited in private plans). The NHIS also accredits HMOs for public (NHIS)and private plans, as well as banks and insurance brokers that participate in the plan. HMOs see this function as a problem and think that the NHIS blurs the boundaries between its operational and regulatory responsibilities.

\section{Challenges facing the scheme}

\section{Coverage for poor people}

Though the Scheme is lauded for providing free coverage for vulnerable population, the coverage is highly restrictive; limited only to children below 5 years old, disabled individuals and prisoners, while ignoring the plight of other equally deserving least-privileged people falling outside this classification. This is not consistent with the practice in other countries operating Health Insurance Scheme systems.

Considering that the Scheme still generates very little funds and thus far from being self sustaining, such argument is not entirely without force. Even so, that is scarcely an adequate justification for total silence on coverage for those who cannot afford payment. Since statutory law recognizes the right of every citizen to "enjoy the best attainable state of physical and mental health," there is an extant legal obligation on the state to remove all 
impediments to health care access. A policy which grants coverage to some but not others, merely on account of the latter's inability to make payments, clearly violates the obligation, unless a feasible alternative route exists.

\section{Poverty as an impediment to access}

The ability of potential enrollees to contribute to the scheme is a product of availability of private resources it is a difficult feat that most people are unlikely to overcome. It is a mistake to think that NHIS can exist independently of other socio-economic dynamics at work in Nigeria. This is true regarding NHIS: it cannot thrive in the absence of a serious commitment to sustainable poverty eradication programs. Poverty poses as much a challenge to the NHIS system deserves greater attention from policy makers in Nigeria.

\section{Non-Compulsory participation}

To ensure viability and sustainability, insurance schemes including NHIS must be able to generate sufficient premiums with which to meet the needs of enrollees. The goal is for the scheme to be self-sustaining. The Scheme allows voluntary participation in all its plans, with the exception of some formal sector employees. Given widespread poverty and the historical reluctance of the people to purchase health insurance. In such circumstances, with insufficient pool of risks and limited premium base, it would be difficult to generate adequate funds to sustain the voluntary plans of the Scheme, possibly leading to a complete collapse of the Scheme.

Purchasing health insurance coverage is perceived as "inviting illness" among the rural illiterates and since illness is to be averted, not invited, this perception deters enrollment. This is a difficult problem considering that, comparatively, the incidence of diseases and illnesses is disproportionately higher among rural than urban residents - a disparity which a voluntary scheme holds little prospect for bridging.

One way of attending to this problem may be by organizing sensitization and education campaigns using already existing institutional structures such as village or town councils as well as cultural and religious organizations to infuse credibility. The success of any government sponsored program, particularly those dependent on direct financial contribution from the population, largely depends on the extent of support the government is able to muster from the people. NHIS in Nigeria suffers from a "packaging" defect, with the result that the Scheme is festered with the same skepticism as several other government policies and programs. The people have understandably grown accustomed to government announcements and "pursuits" of mega-million dollar grandiose projects, many of which meet untimely deaths on the drawing board at various Ministries, Directorates and Agencies.

It is no secret that government projects usually come to naught due, in most cases, to misappropriation of budgeted funds by public officials. Corruption is endemic in Nigeria and Health care is no exception. Seen this way, it becomes easy to understand why people are reluctant to buy into an insurance scheme operated by a government that has done little to earn public trust. There is no guarantee that contributions made out by the people would will in fact be used to provide health care to the contributors as the need arises. Mobilization campaigns via radio, television, newspapers and billboards or through other means are helpful but need to be reinforced with good governance in order to make significant headway. To regain the trust and confidence of the people, transparency and accountability must permeate government institutions and characterize relationship between public officials and the citizenry.

\section{Inequitable health care packages}

The introduction of NHIS came about due to the inequality in the health care system to the least privileged therefore a distinguishing feature of NHIS is equalization of access, whereby everyone with similar health needs is guaranteed same level of care irrespective of the rate of contribution. However, the health care packages available under the Nigerian Scheme 
South American Journal of Public Health

Special Edition May 2016

manifest a different orientation. While formal sector health plans offer a defined minimum package that is equally accessible by enrollees, a different criterion is applied with respect to voluntary informal sector plans, namely, the Urban Self-Employed and Rural Community social health insurance scheme plans. For the two plans, packages vary with the rate of contribution and maintaining different benefit-allocation formula; that is, establishing different levels of benefit based on health plan or rate of contribution, in a sense, retains the much maligned stratified access structure of user fees (income-based access to services)from which the government so desperately wants to distance itself.

\section{Transportation expenses}

Absence of health facilities within proximity to users is a major obstacle to receiving care. In Nigeria, because most of the health facilities are located in cities, far removed from villages, rural dwellers are placed at significant peril when illness strikes. Long distance to hospitals, often on treacherous roads, weighs greatly on patients' ability to seek care; in most cases, forcing them to forego medical consultation until the condition becomes unbearable and invariably more expensive to treat. This is one of the factors blamed for widening ruralurban mortality disparity in the country. This is an area where a reasonable balance needs to be struck among competing demands in order to achieve a desirable outcome.

\section{Measured implementation system}

Relying on the experience of advanced systems, policy makers in Nigeria opted for a measured implementation schema, a phased system that began with coverage for formal sector workers. This was largely driven by concerns about unforeseen contingencies and the belief that such contingencies would be better managed within the context of limited implementation. The target date for universal coverage was set at 2015, presumably after all or at least the major "glitches" have been identified and purged. However, till date, only about $8 \%$ of formal sector employees (less than 2 million people of a population of nearly 140 million), most of whom are federal government employees, are enrolled in the Scheme, as only six States Governments in Nigeria(Kwara, Lagos, Ogun, Ekiti, Niger, Ebonyi)have adopted the National Health Insurance Scheme out of the 36 and the FCT, despite the accreditation of over 66 HMOs by 2012 and 8,000 registered providers. Civil servants employed by state and local governments, whose enrollment should pose little or no logistical difficulties, are not yet part in the Scheme.

Extending coverage to the informal sector, as evident from the experience of mature systems, is notoriously difficult and gets progressively worse as the population increases. Even if the 2015 target is not reached, so long as there is credible evidence of a sustainable progress toward that direction, for instance by achieving substantial coverage, crediting the NHIS with having provided an antidote to the long-standing access crisis in Nigeria that will be considered to be positive. Recently NHIS partnered with MTN a communication provider in Nigeria to help bring affordable healthcare services closer to its subscribers and the nation at large. The rationale for the partnership was to remove the financial barriers to healthcare, thereby affording people access to good healthcare without having to pay out-of-pocket and serve as a means of providing greater access to healthcare for larger segments of a population. The initiative was launched in July 2014 and as a comprehensive mobile health insurance scheme, which is to provide all Nigerians the opportunity to access good, affordable and quality healthcare service wherever the need arises. The scheme will allow subscribers to gain access to pre-defined treatments and also freedom to choose their own Health Maintenance Organization (HMO), and healthcare provider from over 6000 registered partners across Nigeria.

Under the scheme, subscribers will have access to unlimited number of visits to the hospital with at a weekly deduction of $\mathrm{N} 250.00$ (\$1 .6)only. This initiative is new and there is no data as regards the success of the initiative as many Nigerians are skeptical of the programme and see it as a means to enrich the communication provider and the Governments. 


\section{Research methodology}

The research used cross-sectional questionnaire based survey. Data was obtained from clients that work in the Public sector and Private sector this included staff that work for the State Government The source of data included information on demographics, employment information, education, In addition to this, respondents were asked about their current insurance status, and willingness to-pay for health insurance. However, some elements assessing Health care were sampled for primary data collection. These elements include staff and clients. 100 respondents were sampled through questionnaire administration. All the clients were offered the questionnaire and verbal consent was sought. The questionnaires covered areas of socioeconomic characteristics of respondents. A total of 100 questionnaires were administered, all were correctly filled with assistance and were used for analysis.

\section{Results and discussions}

\section{Socio-demographic characteristics}

$45 \%$ were male while $55 \%$ were female clients and were between the ages of 18 - 45 years which is the age where adults are responsible for the health decisions of themselves and their dependents. Post-secondary respondents carried the highest number of people educated $45 \%$ have post-secondary education. About $50 \%$ of the respondents were public servants.

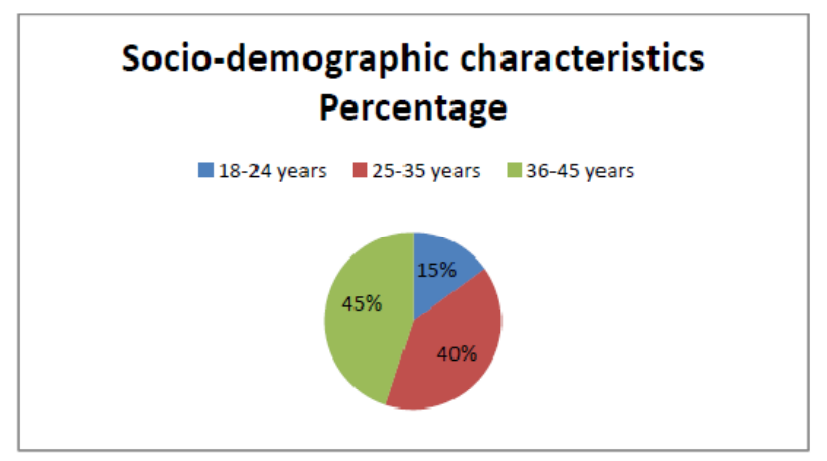

Table 1 Cross tabulation of employment status with education level and marital status

\begin{tabular}{|l|l|l|l|l|l|l|l|}
\hline & \multicolumn{3}{|c|}{ Employed } & \multicolumn{2}{l|}{ Not employed } & Total \\
\hline & & Frequency & Percent & Frequency & Percent & Frequency & Percent \\
\hline \multirow{3}{*}{$\begin{array}{l}\text { Education } \\
\text { level }\end{array}$} & Primary & 0 & 0.0 & 3 & 8.1 & 3 & 5.1 \\
\cline { 2 - 9 } & Secondary & 18 & 81.8 & 30 & 81.1 & 48 & 81.4 \\
\cline { 2 - 8 } & Tertiary & 4 & 18.2 & 4 & 10.8 & 8 & 13.6 \\
\hline \multirow{2}{*}{$\begin{array}{l}\text { Marital } \\
\text { status }\end{array}$} & Married & 22 & 95.7 & 32 & 86.5 & 54 & 90.0 \\
\cline { 2 - 8 } & Single & 14.3 & 4 & 10.8 & 5 & 8.3 & Widowed \\
\cline { 2 - 8 } & 00.0 & 12.7 & 1 & 1.7 & & & \\
\hline
\end{tabular}

Table 1 shows majority of the respondents $81.4 \%(n=48)$ have attained secondary school, of which 30 of them, representing $62.5 \%$ of those who had secondary school education were unemployed at the time of the study. Three of the respondents had attended primary school only, all of whom were unemployed. The results also depicted that majority of the respondents were unemployed at the time of this study. This may also contribute to poor enrollment as they may be more concerned with having basic amenities and not concentrate on health care. 
South American Journal of Public Health

Special Edition May 2016

\section{Method of accessing health care services}

$70 \%$ of the respondents paid for health care from their pockets, while $20 \%$ accessed health care from HMOs and $10 \%$ from free health care.

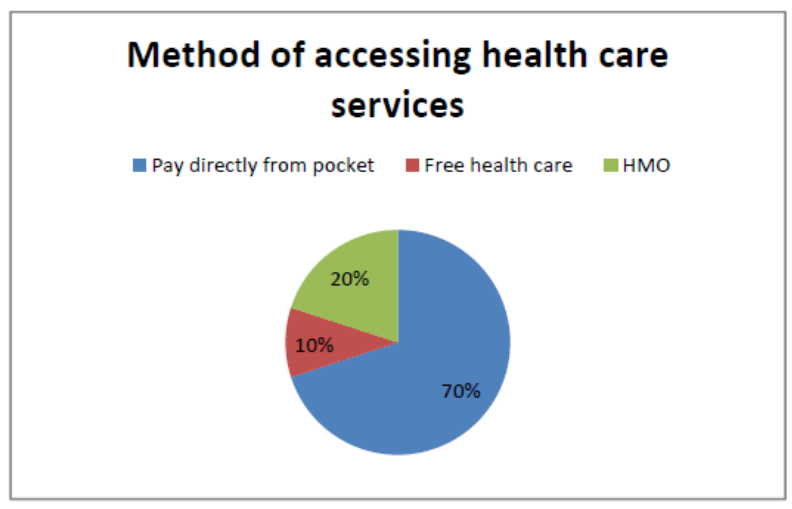

\section{Knowledge of role of health insurance on health care}

$60 \%$ of the respondents had Knowledge of role of health insurance on health care while $40 \%$ did not have knowledge of role of health insurance on health care

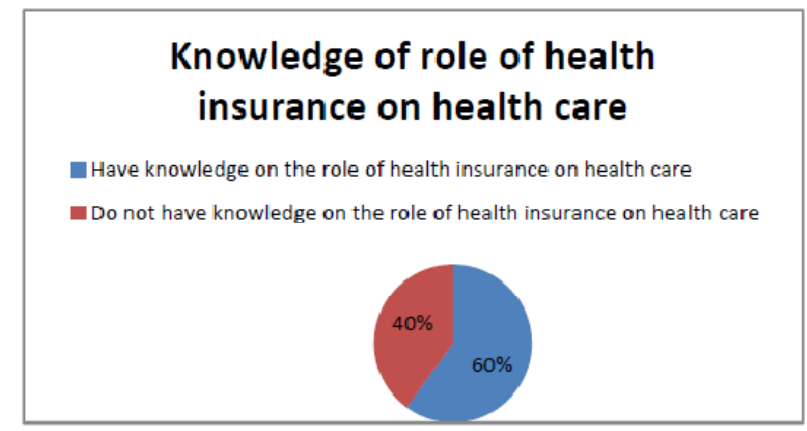

\section{Willingness to pay for health insurance}

$64 \%$ of the respondents said they were not willing to use or register with the NHIS or any HMO while $36 \%$ expressed willing to use or register with the NHIS or any HMO

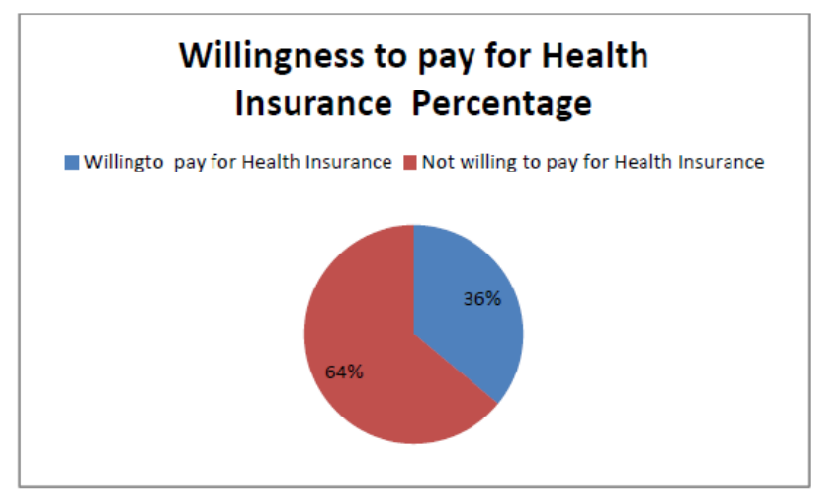

Specifically, we have sought to determine the role of health insurance on health care and to evaluate the success of the NHIS and the role of the HMOs in the uptake of health insurance, we also reviewed the literature on the impact of health insurance and we examined the challenges faced in implementing provision of health insurance. We found $70 \%$ in Akwa Ibom State pay for health care directly and $34 \%$ would pay for health insurance, while $64 \%$ were not willing to pay for health insurance. Some individuals were more likely to enroll for health insurance such as women. 


\section{Conclusion}

In sum, while it seems that most studies on the impact of health insurance show positive effects on access and utilization, it is difficult to generalize the impact as the enrollment has not been as wide spread as planned. Still, given the available literature, we do expect to find an average but not wide spread impact on access and utilization of health care.

\section{Recommendations}

While the study recognizes that the NHIS is a laudable intervention it also discovered that some steps are necessary to ensure its success.

- Proper awareness creation and enlightenment of the scheme should be carried out.

- State governments should implement the registration of civil servants.

- There is a need for proper understanding the role of the HMOs

- The informal sector must be factored in for the NHIS to have adequate impact.

\section{References}

[1.] Amsterdam Institute for International Development (AIID).A Short-Term Impact Evaluation Of The Health Insurance Fund Program In Central Kwara State, Nigeria- Final Draft (March, 2013)

[2.] Arogundade.M.A. The role of Health Maintenance Organizations in the Nigerian National Health Insurance Scheme

[3.] Mc Keon, Kimberley. September 2009. Financing and Business Development Needs of Private Health Care Providers in Nigeria: Market Research Report. Bethesda, MD: Banking on Health, Abt Associates Inc.

[4.] Obiajulu Nnamuchi. The Nigerian Social Health Insurance System and the Challenges of Access to Health Care: An Antidote or a White Elephant? Beazley Institute for Health 15 Law \& Policy, Loyola University Chicago School of Law Medicine and Law Journal, Vol. 28, No. 1, pp. 125-166, 2009 